\title{
Juvenile fibroadenoma of the breast: Treatment and literature review
}

\author{
Wendy K Ng MD ${ }^{1}$, M Amir Mrad MBBS${ }^{2}$, Mitchell H Brown MD MEd FRCSC ${ }^{3}$
}

\begin{abstract}
WK Ng, MA Mrad, MH Brown. Juvenile fibroadenoma of the breast: Treatment and literature review. Can J Plast Surg 2011;19(3):105-107.

It is uncommon to find palpable breast masses in young patients. Generally, such masses are benign. Juvenile fibroadenoma is the most frequent benign tumour of the breast. The present report describes a case involving a 17-year-old girl with unilateral right breast hypertrophy, for whom resection and breast reduction was effectively achieved.

Resection was combined with an aesthetically pleasing outcome through breast reduction, via a wise pattern of reduction with a superior pedicle. While young patients rarely present with breast masses, the consideration of fibroadenoma in these cases is always warranted. The disconcerting appearance of the breasts for adolescents afflicted by such benign masses underscores the importance of achieving aesthetically optimal outcomes and attaining adequate tumour resection for diagnostic purposes through pathological specimens. In the present case, the young patient underwent a procedure that fulfilled both of these valuable goals through careful preoperative planning, pedicle selection and skin resection patterns.
\end{abstract}

Key Words: Breast reduction; Breast tumours; Juvenile fibroadenoma

$\mathrm{t}$ is uncommon to find palpable breast masses in young patients. Generally, such masses are benign, and often occur in females. Fibroadenoma is a major cause of unilateral breast masses in adolescents. It is the most frequent benign tumour of the breast, following fibrocystic disease (1).

Of all fibroadenomas, $0.5 \%$ to $4 \%$ are labelled as juvenile fibroadenomas (2-4). We present a case involving a 17-year-old girl with unilateral breast hypertrophy. We successfully combined resection with an aesthetically pleasing outcome through breast reduction. Our objectives were to familiarize plastic surgeons with this breast mass, and to discuss pedicle selection and skin resection patterns.

\section{CASE PRESENTATION}

A 17-year-old girl presented to our breast centre with unilateral hypertrophy of her right breast. On clinical examination, a large, smooth, rounded mass was palpable in the inferior pole (Figure 1).

The general surgeon at the facility agreed with the provisional diagnosis of fibroadenoma. The patient consented to both tumour resection and a right breast reduction. Patient consent was obtained for a superior pedicle breast reduction and possible free nipple graft depending on extent of resection.

Preoperatively, markings for a wise pattern resection of the skin with a superior pedicle were made. A $45 \mathrm{~mm}$ cookie cutter was used to mark the areola. Intraoperatively, de-epithelialization of a superior pedicle was performed, giving a width of $1.5 \mathrm{~cm}$ below the areolar margin. An incision in the inframammary fold was made with the medial and lateral limb of the wise pattern. The incision was taken down to the pectoralis fascia inferiorly, and the entire inferior pole was elevated above the fascia. At this point, the tumour was palpated to remain contained within the inferior pole, with a smooth surrounding

\section{Un fibroadénome juvénile du sein : le traitement et une analyse bibliographique}

Il est peu courant d'observer des masses mammaires palpables chez de jeunes patients. En général, ces masses sont bénignes. Le fibroadénome juvénile est la tumeur bénigne du sein la plus courante. Le présent rapport décrit le cas d'une fille de 17 ans présentant une hypertrophie unilatérale du sein droit, chez qui une résection et une réduction mammaire ont été couronnées de succès.

La résection s'est associée à un résultat agréable sur le plan esthétique grâce à une réduction mammaire, effectuée au moyen d'un ingénieux mode de réduction par un pédicule supérieur. Les jeunes patients ont rarement des masses mammaires, mais s'ils en ont, il faut toujours envisager un fibroadénome. L'apparence déconcertante des seins des adolescents ayant de telles masses bénignes fait ressortir l'importance d'obtenir des résultats optimaux et de procéder à une résection pertinente de la tumeur afin de poser un diagnostic à l'aide des échantillons pathologiques. Dans le cas présent, la jeune patiente a subi une intervention qui a atteint ces deux objectifs importants, grâce à une planification préopératoire attentive, à la sélection du pédicule et à un profil de résection cutané. capsule. The mass measured $19 \mathrm{~cm}$ (greatest diameter). With continuation of resection on the medial and lateral limb, the tumour was excised along with the surrounding fat and overlying skin. This was accomplished without opening the capsule, and without compromising the superior pedicle (Figure 2).

Due to the benign appearance of the mass, and in association with an intraoperative consult from the general surgeon, no margins were taken with the lesion. Skin flaps were closed in layers using 4-0 monocryl sutures.

Pathological examination revealed a fibroepithelial lesion showing extensive fibrosis. Occasional breast ducts within the lesion showed apocrine metaplasia. No evidence of atypia was present. Overall features were consistent with juvenile giant fibroadenoma.

At one week postoperatively, the wounds healed well, and the patient was pleased with the reduction accomplished by the resection. No follow-up with the general surgeon was necessary, given the benign diagnosis (Figure 3).

\section{FIBROADENOMA}

Fibroadenomas are an abnormality of breast development, but are not considered to be neoplasms (5). These benign tumours contain both connective tissue and epithelial proliferation. While fibroadenomas do not increase the risk of breast cancer, they have rarely been reported to actually contain cancer $(1,2,6,7)$.

Special variants of fibroadenoma include giant fibroadenoma, juvenile fibroadenoma, fibroadenoma in pregnancy and lactation, and multiple fibroadenoma. Giant fibroadenoma is defined to be more than $5 \mathrm{~cm}$ in diameter, and/or weighing more than $500 \mathrm{~g}(5,8-10)$. Juvenile fibroadenoma is described as a giant fibroadenoma occurring in young or adolescent females.

${ }^{1}$ McMaster University, Hamilton; ${ }^{2}$ Department of Surgery, University of Toronto; ${ }^{3}$ Department of Surgery, Women's College Hospital, University of Toronto, Toronto, Ontario

Correspondence: Dr Mitchell H Brown, Women's College Hospital, University of Toronto, 790 Bay Street, Suite 410, Toronto,

Ontario M5S 1N8. Telephone 416-323-6336, fax 416-323-6325, e-mail info@torontoplasticsurgery.com 


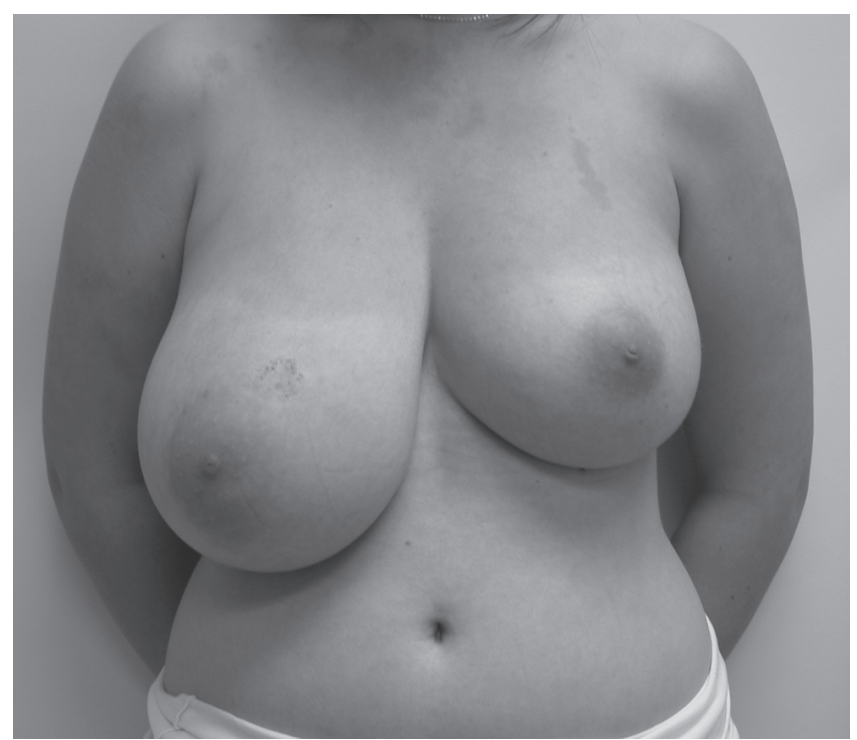

Figure 1) Preoperative image of breasts

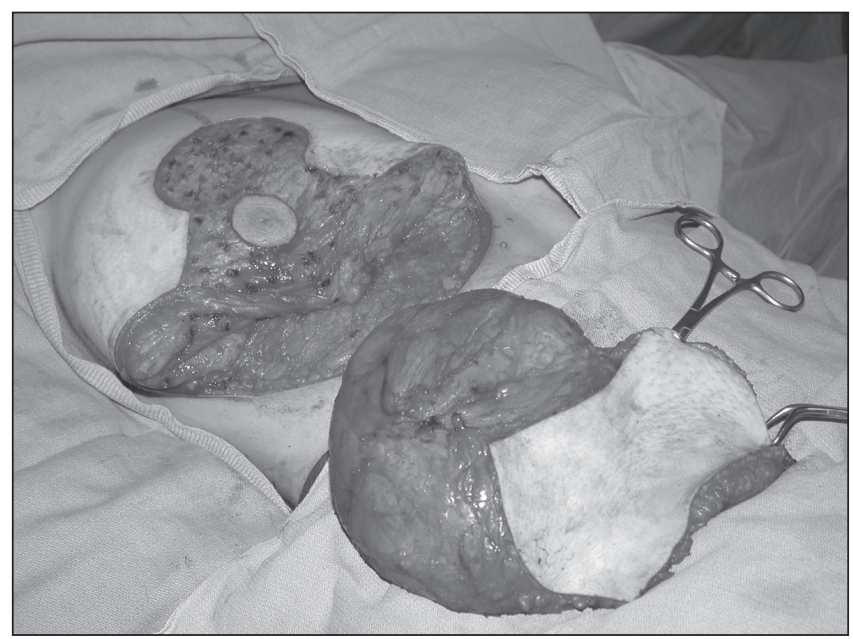

Figure 2) Intraoperative image illustrating pattern of excision of the tumour

\section{Juvenile fibroadenoma}

In contrast to fibroadenomas, the age range at presentation of the variant - juvenile fibroadenoma - tends be between 11 and 18 years, which approximately coincides with the onset of puberty $(2,10)$. Fibroadenoma is extremely rare in very young children, with the earliest known published case in a 13-month-old girl (11). Other differential diagnoses include virginal hypertrophy, fibrocystic disease, cystosarcoma phyllodes, premature thelarche, fibrosarcoma and lymphangioma abscess $(2,10-13)$.

Diagnosis of juvenile fibroadenoma: Diagnosis of a breast mass in an adolescent is often based on history and physical examination. Juvenile fibroadenoma is a painless, solitary and unilateral mass, without evidence of infection, and may double in size within three to six months, reaching $15 \mathrm{~cm}$ to $20 \mathrm{~cm}$ (10). It grows rapidly and distorts overlying skin, with prominent veins. Juvenile fibroadenoma is often cosmetically distressing to the patient (2).

Ultrasound may be more suited to imaging-suspected breast pathology in young patients than mammograms because it better detects masses in fibroglandular breasts than in fatty breasts $(9,14,15)$. Aspiration cytology demonstrates sheets of hyperplastic, benign, ductal epithelial cells with myoepithelial cells and a background of benign bipolar nuclei and blood, without inflammatory fat cells (12). In contrast to phyllodes

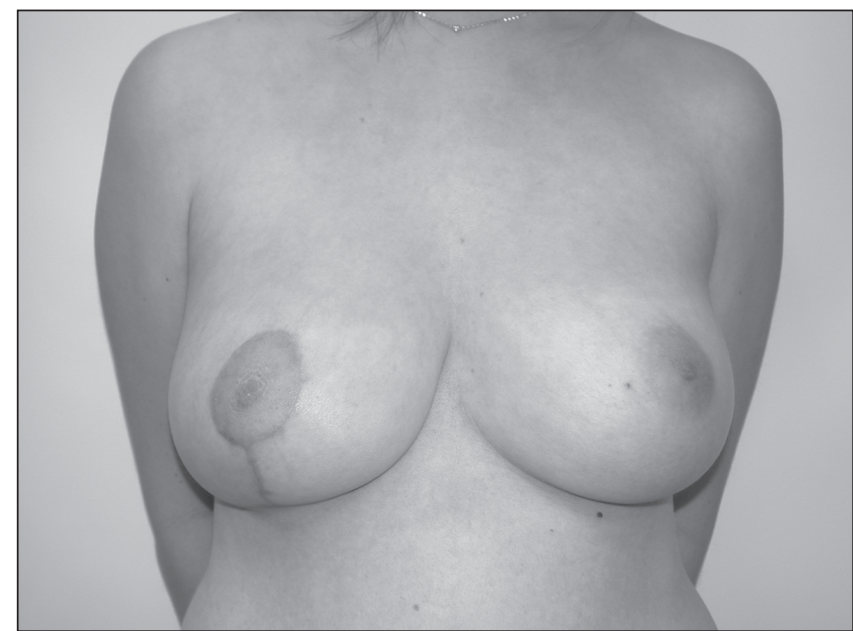

Figure 3) Postoperative (six weeks) image of breasts

tumours, juvenile fibroadenoma often shows hyperplasia of ductal epithelium (15).

Fine-needle aspiration biopsy has been found to be a reliable tool for evaluating masses of the adolescent breast (16), but it requires an experienced cytopathologist. Fine-needle aspiration cannot always differentiate between a phyllodes tumour and a fibroadenoma. This distinction is important because, unlike fibroadenomas, phyllodes tumours require wide excision with negative margins (17).

Finally, incisional biopsy can confirm a diagnosis (11). Histologically, juvenile fibroadenomas appear more cellular with fewer lobular components than simple fibroadenomas (3).

Treatment of juvenile fibroadenoma: Treatment of juvenile fibroadenoma is either excision or observation. In cases of simple fibroadenoma, conservative treatment is favoured because fibroadenoma is not a known risk factor for breast cancer, and $10 \%$ of cases resolve spontaneously. Because juvenile fibroadenomas are large tumours, reconstructive techniques and plastic surgical expertise are frequently required.

Principles of tumour excision and subsequent breast reconstruction include preservation of normal breast parenchyma, adjustment of the skin envelope and symmetrical positioning of the nipple-areola complex bilaterally, and avoidance of iatrogenic amastia via excision of the breast bud in children. (8) Juvenile fibroadenoma has been safely excised in adolescents $(8,10-12,15,18)$.

\section{SUMMARY}

While young patients rarely present with breast masses, the consideration of fibroadenoma in these cases is always warranted. The disconcerting appearance of the breasts for adolescents afflicted by such benign masses underscores the importance of achieving aesthetically optimal outcomes and adequate tumour resection for diagnostic purposes through pathological specimens. In the present case report, a 17-year-old girl underwent a procedure that fulfilled both of these valuable goals through careful preoperative planning, pedicle selection and skin resection patterns.

FINANCIAL DISCLOSURE: The authors have no commercial associations or financial disclosures that might pose or create a conflict of interest with information presented in this article.

\section{REFERENCES}

1. Valdes EK, Boolbol SK, Cohen J, Feldman SM.

Malignant transformation of a breast fibroadenoma to cystosarcoma phyllodes: Case report and review of the literature. Am Surg 2005;71:348-53. 
2. Davis S, Wallace A. A 19 year old with complete androgen insensitivity syndrome and juvenile fibroadenoma of the breast. Breast J 2001;7:430-3.

3. Garcia CJ, Espinoza A, Dinamarca V, et al. Breast US in children and adolescents. Radiographics 2000;20:1605-12.

4. Won KS, Gayed I, Kim EE, Macapinlac H. Juvenile fibroadenoma of the breast demonstrated on 111In-octreotide SPECT and 18F-FDG PET/CT. Eur J Nucl Med Mol Imaging 2007;34:440.

5. Dent D, Cant P. Fibroadenoma. World J Surg 1989;13:706-10.

6. El-Wakeel H, Umpleby H. Systematic review of fibroadenoma as a risk factor for breast cancer. Breast 2003;12:302-7.

7. Sitruk-Ware R, Thalabard J, Benotmane A, Mauvais-Jarvis P. Risk factors for breast fibroadenoma in young women. Contraception 1989;40:251-68.

8. Chang D, McGrath M. Management of benign tumours of the adolescent breast. Plast Reconstr Surg 2007;120:13e-19e.

9. Greenberg R, Skornick Y, Kaplan O. Management of breast fibroadenoma. J Gen Intern Med 1998;13:640-5.
10. Wechselberger G, Schoeller T, Piza-Katzer H. Juvenile fibroadenoma of the breast. Surgery 2002;132:106-7.

11. Jung YS, Lee KJ, Yoon TI, et al. Juvenile fibroadenoma in 13-month-old female child. J Paediatr Child Health 2005;41:78-9.

12. Ahuja A, Seth A. Juvenile fibroadenoma of breast. Indian Pediatr 2005;42:72.

13. Pulzl P, Schoeller T, Tzankov A, Wechselberger G, Schoeller T, Piza-Katzer H. Unilateral breast enlargement 5 years after reduction mammaplasty. Aesthetic Plast Surg 2005;29:404-6.

14. Boothroyd A, Carty H. Breast masses in childhood and adolescence. Pediatr Radiol 1994;24:81-4.

15. Senel SH, Caki BC, Kibar AE. Breast fibroadenoma in female adolescents. Saudi Med J 2007;28:137-8.

16. Pacinda SJ, Ramzy I. Fine-needle aspiration of breast masses: A review of its role in diagnosis and management in adolescent patients. J Adolesc Health 1998;23:3-6.

17. Santen RJ, Sabel MS. Treatment of benign breast disease. UpToDate, 2008.

18. Obuigbo W. Breast fibroadenoma in teenage females. Turkish J Pediatr 2003;45:326-8. 